\title{
Determinação de metais pesados nos camarões (Farfantepenaeus paulensis) consumidos na cidade de Pelotas-RS
}

\author{
A.M.T.P. Pinto, I.M. Hirdes \& P.J. SAnches Filho* \\ GPCA - Grupo de Pesquisa em Contaminantes Ambientais, Instituto Federal Sul-rio-grandense - IF-SUL; Campus Pelotas RS - \\ Tecnologia em Gestão Ambiental, Pelotas, Rio Grande do Sul, Brasil.
}

(Received December 01, 2012; Accept March 17, 2013)

\begin{abstract}
Resumo
O objetivo deste trabalho foi avaliar a contaminação por metais pesados em camarões da espécie Farfantepenaeus paulensis, consumidos na cidade de Pelotas-RS, obtidos dos locais onde são usualmente pescados: Oceano Atlântico e a Laguna dos Patos. As análises foram realizadas no tecido muscular e no exoesqueleto, em duas épocas distintas. As amostras sofreram digestão ácida Nítrico/Perclórica, sendo a determinação de cádmio, chumbo, cobre, cromo e zinco realizada por espectrometria de absorção atômica por chama. Para controle da exatidão e recuperação foi analisado material de referência certificado DORM-3 apresentando recuperações de 71,2 a 98.8\%. Somente o $\mathrm{Pb}$, o $\mathrm{Cu}$, e o $\mathrm{Zn}$ apresentaram concentrações acima do limiar de detecção da metodologia utilizada. Em uma das amostras a concentração de $\mathrm{Pb}$ no exoesqueleto acusou valor acima do permitido pela legislação. Os camarões coletados na Laguna dos Patos apresentaram maiores níveis de contaminação, ainda comprova-se que o exoesqueleto concentra níveis maiores de metais. Os resultados também sugerem que a região da Laguna dos Patos apresenta maior disponibilidade de zinco e chumbo.
\end{abstract}

Palavras-chave: camarão (Farfantepenaeus paulensis), contaminação, Laguna dos Patos, metais pesados, Oceano Atlântico.

\section{Determination of heavy metals in the shrimp (Farfantepenaeus paulensis) consumed in the city of Pelotas-RS}

\begin{abstract}
The objective of this study was to evaluate the heavy metal contamination in shrimp's species Farfantepenaeus paulensis consumed in Pelotas - RS, obtained from the places that they are usually fished: the Atlantic Ocean and Laguna dos Patos in South Brazil. The analyses were performed in the muscle tissue and the exoskeleton, at two different times. The samples were perchloric nitric acid digestion, and the determination of cadmium, lead, copper and zinc spectrometry carried out by flame atomic absorption. To control the accuracy and recovery was analyzed certified reference material DORM-3 showing recoveries of $71.2 \%$ to $98.8 \%$. The concentrations were determined only for $\mathrm{Pb}, \mathrm{Cu}$ and $\mathrm{Zn}$. Particularly, the $\mathrm{Pb}$ in one of the exoskeleton sample had its level above of the limit allowed by law. Shrimps collected in the Patos Lagoon had higher levels of contamination, although it was proven that the exoskeleton has more concentrated levels of metals. The results also suggest that the region of Patos Lagoon has increased availability of zinc and lead.
\end{abstract}

Keywords: Atlantic Ocean, contamination, heavy metals, Laguna dos Patos, the shrimp (Farfantepenaeus paulensis). 


\section{INTRODUÇÃO}

A pesca é uma atividade milenar e, ainda hoje, de considerável importância em todo o mundo, como fonte geradora de alimentos, emprego e renda para vários segmentos econômicos (Bento \& Bemvenuti, 2008). No Brasil, o camarão é o recurso pesqueiro mais explorado nas regiões sudeste e sul (Paiva, 1997). As principais áreas de pesca da região sul se localizam na região estuarina da Laguna dos Patos e na faixa costeira, próximo à cidade de Rio Grande-RS (Haimovici et al., 2006).

A região estuarina compreende aproximadamente $9 \%$ da laguna, sendo habitada por fauna e flora bastante diversa e abundante. Todos os organismos marinhos que dependem do estuário da Laguna dos Patos em alguma etapa do seu ciclo de vida migram através do canal, de comunicação para o oceano. Com uma área de aproximadamente $11.000 \mathrm{~km}^{2}$, a Laguna dos Patos se estende desde a latitude $30^{\circ} 30^{\prime} \mathrm{S}$ até $32^{\circ} 12^{\prime} \mathrm{S}$, próximo à cidade do Rio Grande, onde a laguna se comunica com o Oceano Atlântico através de uma estreita barra (Castello, 1985).

Os estuários e as regiões costeiras são muito utilizados para a disposição de efluentes urbanos e industriais, acarretando a contaminação das águas e da vida marinha por diversos poluentes dentre eles os metais pesados. Do ponto de vista da saúde, o grau de contaminação desses ecossistemas pode colocar em risco a saúde da população que utiliza essas águas tanto para a pesca quanto para o lazer (Maia et. al., 2006).

Um dos maiores problemas da introdução de metais pesados em sistemas aquáticos é a sua bioacumulação, pois o organismo possui a capacidade de reter o contaminante por absorção ou ingestão sem conseguir eliminá-lo, fenômeno que é intensificado pela biomagnificação, processo em que a concentração de contaminantes nos tecidos aumenta à medida que se avança nos níveis tróficos da cadeia alimentar existente nestes compartimentos ambientais, o que faz com que as concentrações de metais nos seres vivos se tornem altamente tóxicas (Markert, 1998). Segundo Câmara (2002), atualmente, muitos casos de morbidade e mortalidade, além de casos de câncer e de intoxicações, tem sido relacionados a fatores ambientais, tais como a exposição à substâncias químicas, como metais pesados por exemplo.

As intoxicações por metais pesados, que ocorrem frequentemente, são causadas por cádmio, cobre, chumbo, cromo, zinco, entre outros. Estes elementos além da sua pouca mobilidade no organismo, alteram as estruturas celulares, as enzimas e substituem metais co-fatores de atividades enzimáticas (Mindell \& Mundis, 1996). Alguns metais como o cromo, na forma trivalente, o cobre e o zinco, são considerados como microelementos essenciais, aqueles que desempenham alguma função biológica nos organismos vivos (Oliveira, 2008), e são encontrados na natureza no ar, água, solo, além dos alimentos. Mesmo sendo essenciais, são considerados tóxicos quando em concentrações elevadas.

Para Azevedo \& Chasin (2003), a concentração de metais no organismo é influenciada por aspectos biológicos (espécie, idade, sexo, etc.), tipo de alimento, quantidade ingerida, ambiente e método de preparação culinária. Em resumo, o efeito deletério do contaminante no organismo depende de todos os fatores da toxicocinética, além das próprias especificidades do contaminante. Tendo em vista que o camarão-rosa (Farfantepenaeus paulensis) é o principal recurso pesqueiro explorado na região (Haimovici et al., 2006), este pode ser uma das fontes de metais a serem ingeridas pela população local.

As espécies de Farfantepenaeus apresentam adultos e juvenis em áreas separadas. Os juvenis estão nos estuários e os adultos em mar aberto. Isso leva estas espécies a apresentarem dois movimentos migratórios principais: as larvas e pós-larvas são levadas pelas correntes marinhas da zona de reprodução para os estuários e baías; enquanto que depois de crescerem e atingirem o estágio de pré-adultos, se deslocam dos estuários para as zonas de reprodução no mar (Manzoni \& D'Incao, 2007).

A comercialização do camarão-rosa é realizada por muitos pescadores que fazem da pesca seu meio de subsistência. Eles são vendidos para a população local e também para o Mercado Público Central de Pelotas, que os revende para a população em geral. Com a finalidade de avaliar os níveis de contaminação nesta importante fonte de proteína para a população este trabalho tem como objetivo a determinação do teor de metais, cádmio, cobre, chumbo, cromo e zinco em camarões da espécie Farfantepenaeus paulensis, coletados na Laguna dos Patos e na região oceânica costeira do extremo sul do Rio Grande do Sul.

\section{MATERIAL E MÉTODOS}

\section{Area de estudo}

Foram analisadas amostras de camarões pescados na região estuarina da Laguna dos Patos, mais precisamente na Barra do Saco do Laranjal, conforme indicado na Figura 1A, e na região litorânea da cidade de Rio grande/Cassino (Oceano Atlântico), Figura 1B. A espécie foi identificada como camarão-rosa (Farfantepenaueus paulensis), espécie mais comumente consumida na região.

\section{Coleta de amostra}

As amostras dos crustáceos foram adquiridas em duas épocas, dezembro de 2011 (Coleta I) e março de 2012 (Coleta II). Durante a Coleta I foram obtidos camarões da Laguna dos Patos e do Oceano Atlântico, na Coleta II apenas camarões da Laguna dos Patos.

\section{Preparação dos materiais para análise}

Toda a vidraria utilizada neste trabalho permaneceu previamente em imersão por 24 horas em ácido nítrico $\left(\mathrm{HNO}_{3}\right)$ a $10 \%$, com a finalidade de evitar a contaminação por metais (Wu \& Batley, 1995). 


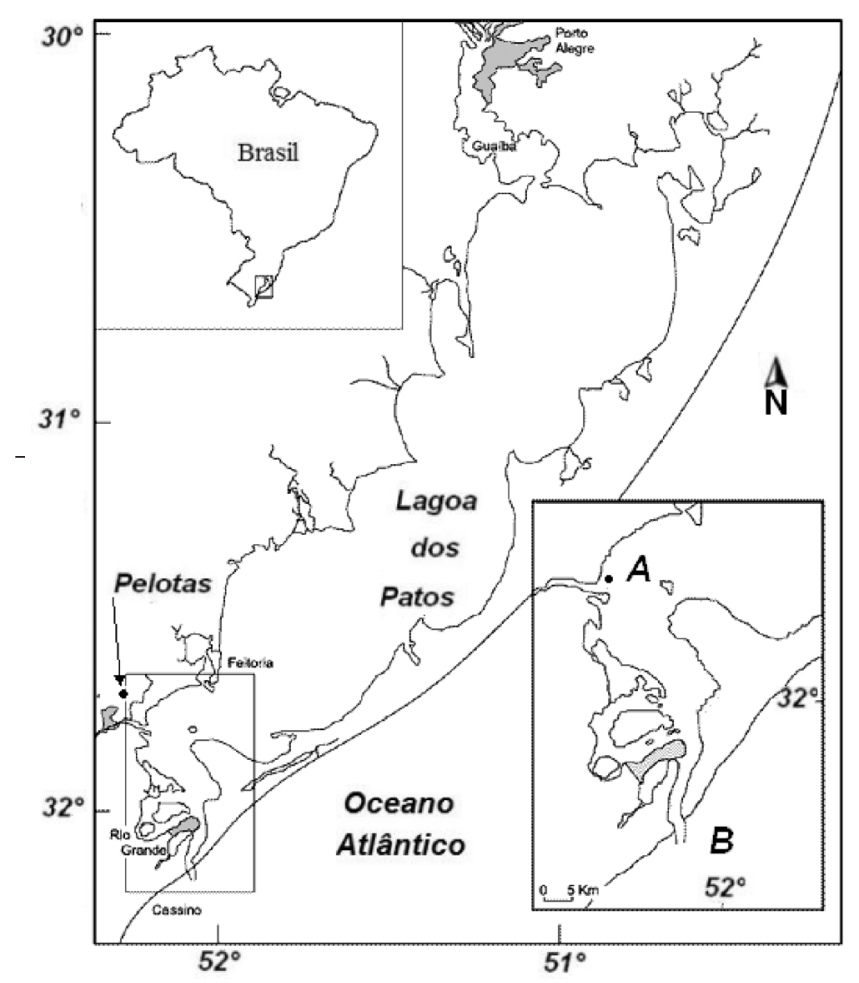

Figura 1: Localização dos pontos de amostragem. Ponto A: Barra do Saco do Laranjal. Ponto B: Região Litorânea da cidade de Rio Grande/Cassino (Oceano Atlântico). Fonte: adaptada de MATTHIENSEN et al., 1999.

\section{Preparação de amostras para análise}

$200 \mathrm{~g}$ das amostras tiveram seus indivíduos pesados e seu comprimento determinado com auxilio de um paquímetro.

As amostras à temperatura ambiente foram dissecadas sendo separadas o exoesqueleto do tecido muscular. As amostras destinadas à determinação do metal foram secas a $60{ }^{\circ} \mathrm{C}$ até peso constante. A determinação da umidade foi feita em forno estufa a $105^{\circ} \mathrm{C}$ até o peso manter-se constante. A diferença de peso foi calculada, obtendo-se, assim a \% de umidade (Instituto Adolfo Lutz, 1985).

\section{Reagentes}

Todos os reagentes utilizados foram de grau analítico. Ácido nítrico concentrado $(65 \% \mathrm{p} / \mathrm{p})$ e ácido perclórico $\left(\mathrm{HClO}_{4}\right)(70 \% \mathrm{p} / \mathrm{p})$ foram utilizados na digestão das amostras. Foram preparados padrões a partir das soluções estoques de $1000 \mathrm{mg} \mathrm{L}^{-1}$ de $\mathrm{Cd}, \mathrm{Pb}, \mathrm{Cu}, \mathrm{Cr}$ e de $\mathrm{Zn}$ todos, da marca Titrisol@ - Merck . Para avaliação da exatidão dos resultados foi analisada amostra de referência certificada DORM-3 (National Research Council Canadá), $[\mathrm{Cd}]=0,290 \pm 0,02$, $[\mathrm{Pb}]=0,395 \pm 0,05,[\mathrm{Cu}]=15,50 \pm 0,63,[\mathrm{Cr}]=1,89 \pm 0,17$ $\mathrm{e}[\mathrm{Zn}]=51,30 \pm 3,10 \mathrm{mg} \mathrm{kg}^{-1} \mathrm{em}$ base seca. Para as diluições usou-se água Milli - Q.

\section{Método de digestão:}

Dois gramas da amostra foram digeridas com uma mistura de $\mathrm{HNO}_{3}$ e $\mathrm{HClO}_{4}$ concentrados $(2: 1 \mathrm{v} / \mathrm{v})$, aquecidas a $60^{\circ} \mathrm{C}$ por 72 horas e avolumadas a $25 \mathrm{~mL}$ (Dural et al., 2007).

As digestões das amostras foram feitas em quintuplicata. Todas as análises foram acompanhadas por determinações em brancos.

\section{Determinação de metais}

Após a digestão, a determinação quantitativa dos metais foi executada por espectrometria de absorção atômica por chama com equipamento da marca Perkin Elmer, modelo A Analyst 200, utilizando chama ar/acetileno, com valores de comprimento de onda de cada elemento e corrente da lâmpada de, respectivamente, $\mathrm{Cd}: 228,8 \mathrm{~nm}$ e $3,0 \mathrm{~mA} ; \mathrm{Pb}: 217,0 \mathrm{~nm}$ e $5,0 \mathrm{~mA} ; \mathrm{Cu}: 324,7 \mathrm{~nm}$ e $3,0 \mathrm{~mA}$; Cr: $357,9 \mathrm{~nm}$ e $6,0 \mathrm{~mA} ; \mathrm{Zn}$ : $213,9 \mathrm{~nm}$ e $5,0 \mathrm{~mA}$.

As leituras das amostras foram feitas em triplicata. Para fins de comparação com a legislação, as concentrações de metais foram convertidas de peso seco (p.s) para peso úmido (p.u). As curvas analíticas foram traçadas a partir de dados de soluções diluídas da solução estoque de $\mathrm{Cd}, \mathrm{Pb}, \mathrm{Cu}$, $\mathrm{Cr}$ e $\mathrm{Zn}$, no intervalo de concentrações de 0,2 à $5,0 \mathrm{mg} \mathrm{L}^{-1}$, obtendo-se os coeficientes de correlação angular e linear. A solução de referencia constituída de $\mathrm{Cd}, \mathrm{Pb}, \mathrm{Cu}, \mathrm{Cr}$ e $\mathrm{Zn}$ foi medida 11 vezes para determinação da precisão das medidas de absorbância do equipamento.

O limite de quantificação (LQ) e o limite de detecção (LD), foram calculados considerando-se o sinal médio do branco ( $\mathrm{N}=10$ leituras). Para definir o LQ considerou-se a média das leituras +10 desvios padrão (SD). Para o LD considerou-se a média do branco + 3 SD, conforme IUPAC (1997).

\section{Tratamento estatístico}

A diferença entre as médias das concentrações de metais foi avaliada pelo Teste $t$ (de student) com um nível de significância de 5\% normalmente utilizado, como no trabalho de Lopes (2006). Foram testadas as diferenças entre as médias do exoesqueleto e tecido muscular, da Laguna dos Patos e Oceano Atlântico, assim como duas épocas distintas. A análise estatística foi conduzida utilizando a ferramenta de análise de dados do software Excel 2010.

\section{RESULTADOS E DISCUSSÃO}

Os valores encontrados de comprimento e peso nas coletas foram de, respectivamente, na Coleta I Laguna dos Patos 10,2 $\mathrm{cm} \pm 1,0$ e $5,0 \mathrm{~g} \pm 2,2$ reunindo 40 indivíduos, na Coleta I Oceano Atlântico $10,8 \mathrm{~cm} \pm 0,8$ e 6,3 $\mathrm{g} \pm 2,1$ reunindo 30 indivíduos e na Coleta II Laguna dos Patos $10,5 \mathrm{~cm} \pm 1,0$ e 5,6 g $\pm 2,3$ reunindo 36 indivíduos. Na Laguna dos Patos foi observado um relativo aumento de tamanho e massa dos camarões dentro do estuário e dentro da mesma campanha de coleta os camarões capturados no Oceano Atlântico apresentaram tamanhos maiores, tal fato reflete diretamente na maior bioconcentração de metais nos indivíduos maiores. 
O camarão F. brasiliensis em sua fase juvenil é, normalmente, encontrado em associação com algas e/ou gramíneas, pois se alimenta de pequenos organismos ali associados, o que leva os jovens a terem valores de metais mais baixos ao serem comparados aos adultos (Costa \& Costa, 2004).

Na Tabela 1 são mostrados os parâmetros de mérito dos analitos: os coeficientes angular(a), linear (b), de correlação linear $\left(\mathrm{r}^{2}\right)$, desvio padrão relativo (RSD), Limite de Detecção (LD), Limite de Quantificação (LQ) do equipamento, também, o LD e o LQ do método considerando $80 \%$ de umidade e massa de $2 \mathrm{~g}$ de amostra, para as coletas I e II. Podemos observar a resposta linear para faixa de trabalho com o $\mathrm{r}^{2}$ variando de 0,981 a 0,999 , refletindo o excelente desempenho do equipamento. A precisão foi comprovada através do RSD variando de 0,50 a $7,8 \%$, sendo menor que $2 \%$ para maioria dos elementos, influenciou diretamente no LD e LQ, confirmada a partir do estudo da análise da solução de referência $0,8 \mathrm{mg} \mathrm{L}^{-1}$ constituído de $\mathrm{Cd}, \mathrm{Pb}, \mathrm{Cu}, \mathrm{Cr}$ e $\mathrm{Zn}$.

A exatidão do método é definida como sendo a concordância entre o resultado de um ensaio e o valor de referência aceito como convencionalmente verdadeiro. Os processos normalmente utilizados para avaliar a exatidão de um método são, entre outros: uso de materiais de referência, participação em comparações interlaboratoriais e realização de ensaios de recuperação (INMETRO, 2007). Através da recuperação do material certificado DORM-3 obteve-se valores satisfatórios, variando de $71,2 \% \pm 0,4$ para o $\mathrm{Cu}, 73,9 \% \pm 1,5$ para o $\mathrm{Zn}, 80,6 \% \pm 0,1$ para $\mathrm{Pb}$ e $\mathrm{Cr}$ com $98,8 \% \pm 5,3$ confirmando a exatidão do método. $\mathrm{O}$ único metal que não obteve recuperação foi o $\mathrm{Cd}$, não sendo detectado no material de referência, pois o valor encontra-se abaixo do Limite de Quantificação do método.

Os resultados obtidos para a concentração de cádmio, chumbo, cobre, cromo e zinco no tecido muscular e no exoesqueleto nas duas coletas, a umidade e o Limite Máximo Tolerável (LTM) estabelecido pela legislação brasileira (Decreto Lei 55.8711965), são apresentados na Tabela 2. A umidade variou entre 72,74 e $84,41 \%$. As concentrações foram detectadas somente para o $\mathrm{Pb}, \mathrm{Cu}$ e $\mathrm{Zn}$. Tais metais também, foram encontrados por outros pesquisadores conforme Tabela 3 .

$\mathrm{O}$ exoesqueleto apresentou valores $\mathrm{de} \mathrm{Pb}$ maiores que o limite aceitável pela legislação na coleta II (Laguna dos Patos exoesqueleto), dentro do LTM na coleta I (Laguna dos Patos) e não foi detectado na coleta I (Oceano Atlântico). Na região sul do
Brasil o exoesqueleto não faz parte dos hábitos alimentares, em sua grande maioria, contudo, tem como destino final o descarte diretamente em solo ou em efluentes, o que evidentemente resulta em grande impacto ambiental, (Assis \& Britto, 2008). Segundo KNORR (1991), mundialmente em torno de 120.000 ton ano ${ }^{-1}$ de resíduos da indústria pesqueira passíveis de reaproveitamento são descartados, o que correspondem com base nos resultados deste estudo, para chumbo no exoesqueleto (coleta II) à cerca de 505,2 $\mathrm{kg}$ ano ${ }^{-1} \mathrm{de} \mathrm{Pb}$ disponível no meio ambiente.

Para o cobre, os resultados obtidos foram maiores para a Laguna dos Patos na coleta II, em seguida para o Oceano Atlântico e menores para a Laguna dos Patos na coleta I, todos abaixo do LTM. Os teores de Zn permaneceram maiores no Oceano Atlântico, seguido da Laguna dos Patos na coleta II e da Laguna dos Patos na coleta I, também abaixo do LTM.

$\mathrm{Na}$ Tabela 3 encontram-se comparações dos valores encontrados em outros trabalhos relacionados ao mesmo estudo. Todos os autores encontraram concentrações maiores no exoesqueleto do que no tecido muscular, com exceção de Lopes (2006) e Wu \& Yang (2011), que constataram concentrações maiores de zinco no tecido muscular.

A partir dos resultados obtidos, no nível de significância de $5 \%$, pode-se afirmar que as concentrações de metais encontradas no exoesqueleto são maiores que no tecido muscular. Isto pode ser explicado pela presença da quitina, substância encontrada na matriz da estrutura esquelética e revestimento de invertebrados, pois esta substância forma com metais como o cobre um complexo extremamente estável (Campana-Filho et al., 2007). Estes resultados estão de acordo com a afirmação de White \& Rainbow (1984), de que os metais podem associar-se com o exoesqueleto de crustáceos através de processos de adsorção. A quitina e proteínas associadas têm muitos grupos contendo hidroxilas, imidazol e sulfidrilas que podem servir como sítios de ligação para metais catiônicos. Esses sítios são comuns na epicutícula de crustáceos, aumentando o potencial para adsorção.

Pode-se afirmar que as concentrações de metais em camarões na Laguna dos Patos foram maiores que os do Oceano Atlântico. Os estuários são ecossistemas de grande produtividade, devido, principalmente, ao derramamento de nutrientes inorgânicos provindos do continente, entrada das águas do mar, resíduos orgânicos urbanos e de atividades

Tabela 1 - Parâmetros de mérito dos analitos: coeficientes angular (a); linear (b); de correlação linear ( ${ }^{2}$ ); Desvio Padrão Relativo (RSD); Limite de Detecção do aparelho (LD); Limite de Quantificação do equipamento (LQ); e o LD e o LQ do método considerando 80\% de umidade e massa de 2 g de amostra.

\begin{tabular}{|c|c|c|c|c|c|c|c|c|c|c|}
\hline \multicolumn{6}{|c|}{ Coleta I } & \multicolumn{5}{|c|}{ Coleta II } \\
\hline Parâmetros & $\mathrm{Cd}$ & $\mathrm{Pb}$ & $\mathrm{Cu}$ & $\mathrm{Cr}$ & $\mathrm{Zn}$ & $\mathrm{Cd}$ & $\mathrm{Pb}$ & $\mathrm{Cu}$ & $\mathrm{Cr}$ & $\mathrm{Zn}$ \\
\hline A & 0,349 & 0,043 & 0,120 & 0,018 & 0,292 & 0,117 & 0,015 & 0,066 & 0,017 & 0,155 \\
\hline$r^{2}$ & 0,998 & 0,992 & 0,996 & 0,981 & 0,999 & 0,998 & 0,997 & 0,999 & 0,999 & 0,998 \\
\hline RSD \% & 0,50 & 1,80 & 1,40 & 2,20 & 1,70 & 1,54 & 7,80 & 0,74 & 3,46 & 1,30 \\
\hline LD mg kg-1 & 0,24 & 0,45 & 0,06 & 0,93 & 0,02 & 0,44 & 0,45 & 0,06 & 0,65 & 0,14 \\
\hline LQ mg kg ${ }^{-1}$ & 0,26 & 0,48 & 0,30 & 1,28 & 0,93 & 1,04 & 1,54 & 0,57 & 2,23 & 1,21 \\
\hline
\end{tabular}


Tabela 2 - Concentração de metais pesados ( $\mathrm{mg} \mathrm{kg}^{-1} \pm \mathrm{SD}$ ) em base úmida, umidade (\%) e Limite Máximo Tolerável (LTM) estabelecido pela legislação brasileira $\left(\mathrm{mg} \mathrm{kg}^{-1} \pm \mathrm{SD}\right)$ em base úmida.

\begin{tabular}{|c|c|c|c|c|c|c|c|}
\hline & & $\begin{array}{c}\text { Umidade } \\
(\%)\end{array}$ & $\begin{array}{c}\mathrm{Cd} \\
\left(\mathrm{mg} \mathrm{kg}^{-1}\right)\end{array}$ & $\begin{array}{c}\mathrm{Pb} \\
\left(\mathrm{mg} \mathrm{kg}^{-1}\right)\end{array}$ & $\begin{array}{c}\mathrm{Cu} \\
\left(\mathrm{mg} \mathrm{kg}^{-1}\right)\end{array}$ & $\begin{array}{c}\mathrm{Cr} \\
\left(\mathrm{mg} \mathrm{kg}^{-1}\right)\end{array}$ & $\begin{array}{c}\mathrm{Zn} \\
\left(\mathrm{mg} \mathrm{kg}^{-1}\right)\end{array}$ \\
\hline \multirow{3}{*}{ 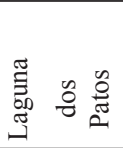 } & \multicolumn{7}{|c|}{ I Coleta } \\
\hline & Exoesqueleto & 80,06 & ND & $1,81 \pm 0,06^{\mathrm{a}}$ & $1,49 \pm 0,07^{\mathrm{d}}$ & ND & $5,55 \pm 0,12^{\mathrm{j}}$ \\
\hline & Tecido muscular & 84,41 & ND & $\mathrm{D}$ & $0,45 \pm 0,02^{\mathrm{e}}$ & ND & $3,77 \pm 0,14^{k}$ \\
\hline \multirow{2}{*}{$\begin{array}{l}\text { O } \\
\text { हूँ } \\
\text { O }\end{array}$} & Exoesqueleto & 72,74 & ND & ND & $4,42 \pm 0,73^{\mathrm{f}}$ & ND & $9,41 \pm 0,96^{1}$ \\
\hline & Tecido muscular & 80,44 & ND & ND & $1,32 \pm 0,17^{\mathrm{g}}$ & ND & $6,63 \pm 0,23^{\mathrm{m}}$ \\
\hline \multirow{4}{*}{ 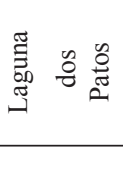 } & \multicolumn{7}{|c|}{ I I coleta } \\
\hline & Exoesqueleto & 73,82 & ND & $4,21 \pm 0,63^{\mathrm{b}}$ & $7,67 \pm 0,76^{\mathrm{h}}$ & ND & $9,24 \pm 1,26^{\mathrm{n}}$ \\
\hline & Tecido muscular & 79,31 & ND & $1,66 \pm 0,11^{\mathrm{c}}$ & $2,68 \pm 0,11^{\mathrm{i}}$ & ND & $5,03 \pm 0,69^{\circ}$ \\
\hline & & Base úmida & 1,00 & 2,00 & 30,00 & 0,10 & 50,00 \\
\hline
\end{tabular}

D: Detectado, valor $>$ LD e $<$ LQ. ND: Não Detectado, valores $<$ LQ e $<$ LD. Letras sobrescritas diferentes representam diferenças significativas de concentrações dos resultados.

agrícolas. Chuvas, salinidade e vento estão mutuamente relacionados e condicionam diretamente os padrões biológicos e produtivos do ecossistema (Mirlean et al.,2003).

Pode-se afirmar que na coleta II (março) houve um aumento nas concentrações de metais, provavelmente deve-se ao fato de em março o período de residência do camarão na Laguna dos Patos foi maior, podendo mostrar um enriquecimento de metais nesse período, justificando também o que diz Carvalho et al. (1999), na qual observou que março é período seco e que em bacias de drenagem, onde a principal fonte de metais são esgotos urbanos, apresentam maiores concentrações nos meses onde o volume de água é menor. Os dados obtidos por Betemps \& Sanches Filho, confirmam a presença destes metais no Saco do Laranjal destacando $\mathrm{Zn}$ e $\mathrm{Pb}$ como elementos majoritários nos sedimentos da Laguna dos Patos. Geralmente a alta concentração desses metais em camarão é devida principalmente à grande ingestão de sedimentos (Jackson et al., 2005).

\section{CONCLUSÃO}

Atravésdesseestudoconstatou-sequeoscamarõesconsumidos na região de Pelotas (RS) apresentaram concentrações de metais $(\mathrm{Cd}, \mathrm{Cr}, \mathrm{Cu}, \mathrm{Pb}$ e $\mathrm{Zn})$ em valores considerados abaixo das concentrações letais e toleráveis estabelecidas para o consumo humano, tais resultados sugerem estar em boa qualidade para o consumo. Durante o período amostrado camarões coletados a partir da Laguna dos Patos, local favorável a deposição de contaminantes, apresentaram um enriquecimento em metais pesados, ainda comprova-se que o exoesqueleto concentra níveis maiores destes analitos. Dentre os metais destacaram-se Zinco e Chumbo estando suas concentrações abaixo dos parâmetros exigidos, exceto para a segunda coleta na Laguna dos Patos, no exoesqueleto, obtendo-se um valor acima do permitido pela legislação. Os resultados também indicam que a região da Laguna dos Patos apresenta maior disponibilidade de zinco e chumbo.

Tabela 3 - Comparação das referências, concentração de metais pesados ( $\left.\mathrm{mg} \mathrm{kg}^{-1} \pm \mathrm{SD}\right)$ em base seca.

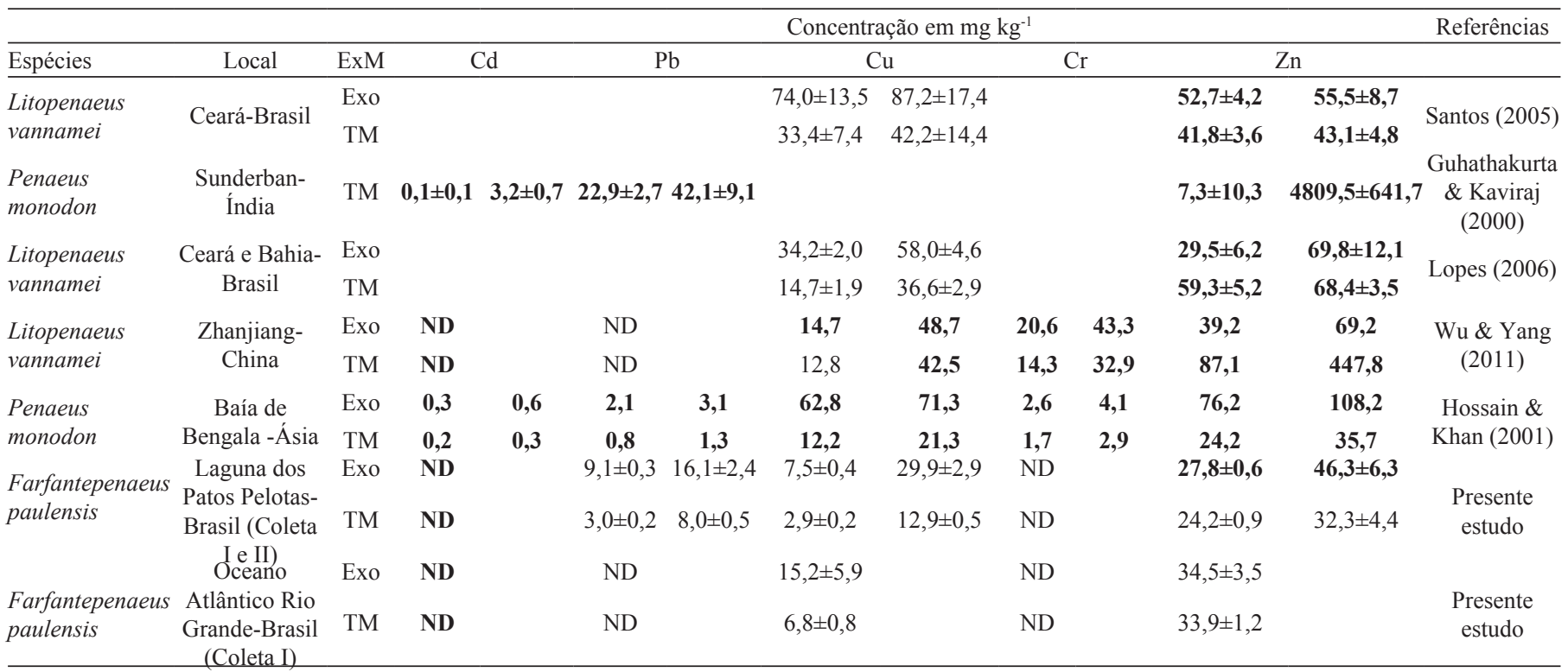

TM: Tecido muscular. Exo: Exoesqueleto. ND: Não Detectado, valores $<$ LQ e $<$ LD. ExM: tecidos analisados 


\section{AGRADECIMENTOS}

Agradecemos ao curso de Química do IFSUL Campus Pelotas - RS, a Pró-reitoria de Pesquisa, Inovação e Pósgraduação - PROPESP - IFSUL e ao Grupo de Pesquisa em Contaminantes Ambientais - GPCA, pela colaboração de essencial importância neste trabalho.

\section{REFERÊNCIAS}

ASSIS, O. B. G. \& BRITTO, D., 2008, Processo básico de extração de quitinas e produção de quitosana a partir de resíduos da carnicicultura. R. Bras. Agrociencia, Pelotas, 14 (1): 91-100.

AZEVEDO, F.A. \& CHASIN, A.M., 2003, As bases Toxicológicas da Ecotoxicologia. São Paulo, Intertox, pp. $151-156$.

BENTO, D.M. \& BEMVENUTI, M.A., 2008, Os peixes de água doce da pesca artesanal no sul da Lagoa dos Patos RS - Subsídios ao ensino escolar. Cadernos de Ecologia Aquática, 3 (2): 33-41.

BETEMPS, G. R., SANCHES FILHO, P. J., 2012, Estudo sazonal de metais pesados no sedimento do Saco do Laranjal - Pelotas - RS. J. Braz. Soc. Ecotoxicol., 7 (2): 79-84. http://dx.doi.org/10.5132/ jbse.2012.02.012.

CÂMARA V.M., 2002, Epidemiologia e ambiente. In: Medronho, $R$. A. (ed), Epidemiologia. São Paulo: Atheneu, pp. 371-383.

CAMPANA-FILHO, S.P., BRITTO, D., CURTI, C., ABREU, F.R., CARDOSO, M.B., BATTISTI, M.V., SIM, P.C., GOY, R.C., SIGNINI, R. \& LAVALL, R.L., 2007, Extração, estruturas e propriedades de $\alpha$ - e $\beta$-quitina. Quím. Nova, 30 (3): 644-650. http://dx.doi.org/10.1590/S0100-40422008000800019.

CARVALHO, C.E.V., OVALLE, A.R.C., REZENDE, C.E., SALOMÃO, M.S.M.B., MOLISANI, M.M. \& LACERDA, L.D., 1999, Seasonal variation of particulate heavy metals in the Lower Paraíba do Sul River Drainage Basin, R.J. Brazil. Env. Geology, 37 (4): 297-302.

CASTELLO, J.P., 1985, The ecology of consumers from dos Patos Lagoon estuary, Brazil. In: Yanes-Aranciba, A. (ed), Fish Community Ecology in Estuaries and Coastal Lagoons Towards an Ecosystem Integration. México: UNAM Press, pp. 383-406.

COSTA, F. A. A., COSTA, R. C., 2004, Níveis de metais pesados no camarão-rosa Farfantepenaeus brasiliensis (Crustacea, Decapoda) na enseada de Ubatuba, Ubatuba, São Paulo. Rev. biociên., Taubaté, 10 (4): 199-203.

Decreto Lei no 55.781, de 26 de março de 1965. "Princípios Gerais para o Estabelecimento de Niveis Máximos de Contaminantes Químicos em Alimentos" e seu anexo "Limites máximos de tolerância para contaminantes inorgânicos”. Disponível em: $<$ http://www.anvisa.gov.br/legis/decretos/55871_65.htm $>$. Acesso em: 10 de maio de 2012.

DURAL, M.; GÖKSU, M.Z.L. \& ÖZAK, A.A., 2007, Investigation of heavy metal levels in economically important fish species captured from the Tuzla lagoon. Food Chem. 102: 415-421. http://dx.doi.org/10.1016/j.foodchem.2006.03.001

GUHATHAKURTA, H. \& KAVIRAJ, A., 2000, Concentração de metais pesados na água, sedimentos, camarão (Penaeus monodon) e Tainha (Liza parsia) em algumas lagoas de água salobra de Sunderbans, Índia. Mar. Pollut. Bull., 40 (11): 914920. http://dx.doi.org/10.1016/S0025-326X(00)00028-X.

HAIMOVICI, M., VASCONCELOS, M. \& KALIKOSKI, D. C., ABDALAH, P., CASTEllo, J.P. \& HELlEBRANDT, D., 2006, Diagnóstico da Pesca no Litoral do estado do Rio Grande do Sul. Belém. Editora Universitária UFPA, pp. 157-180.

HOSSAIN, S. \& KHAN, Y.S.A, 2001, Trace metals in Penaeid shrimp and Spiny lobster from the Bay of Bengal. Sci. Asia, 27: 165-168.

INMETRO - Instituto Nacional de Metrologia, Normalização e
Qualidade Industrial, 2007, Orientação sobre validação de métodos de ensaios químicos. DOQ-CGCRE-008, revisão 02, $14 \mathrm{p}$.

Instituto Adolfo Lutz, 1985, Normas Analíticas do Instituto Adolfo Lutz. 3a ed. São Paulo, v.1, 533p.

IUPAC - International Union of Pure and Applied Chemistry, 1997, Chemistry Compendium of Chemical Terminology. 2nd Edition.

JACKSON, R. N., BAIRD, D., ELS, S., 2005, The effect of the heavy metals lead $(\mathrm{Pb} 2+)$ and zinc $(\mathrm{Zn} 2+)$ on the brood and larval development of the burrowing crustacean, Callianassa kraussi. Water $S A, 31$ (1), 107-116. Disponível em: <http://www. wrc.org.za> Acesso em: novembro de 2012.

KNORR, D., 1991, Recovery and utilization of chitin and chitosan in food processing waste management. Food Technol., 45(1): 114-123.

LOPES, D.V., 2006, Acúmulo de metais traço Cobre (Cu) e Zinco (Zn) em viveiros de cultivo de camarão (Litopenaeus vannamei). Tese (Mestrado em Ciências Marinhas Tropicais), Universidade Federal do Ceará, Fortaleza, 77p.

MAIA, C.B.; ALMEIDA, A.C.M. \& MOREIRA F.R., 2006, Avaliação do teor de chumbo em mexilhões da espécie Perna perna na região metropolitana da cidade do Rio de Janeiro. $J$. Braz. Soc. Ecotoxicol., 1 (2): 195-198. http://dx.doi.org/10.5132/ jbse.2006.02.020

MANZONI, J. \& D'INCAO, F., 2007, Bioecologia dos crustáceos decápodos: Proposta para ambientalização de currículo. Cadernos de Ecologia Aquática, 2 (1): 13-18.

MARKERT, B., 1998, Distribution and biogeochemistry of inorganic chemicals in the environment, In: Shüürmann, G, Market, B. (eds) Ecotoxicology. John Wiley \& Sons, Amsterdam, pp.165222.

MATTHIENSEN, A.; YUNES, J. S. and CODD, G. A., 1999, Ocorrência, distribuição e toxicidade de cianobactérias no estuário da Lagoa dos Patos, RS. Rev. Bras. Biol. 59 (3): 361 376. http://dx.doi.org/10.1590/S0034-71081999000300002

MINDELL, E. \& MUNDIS, H., 1996, Vitaminas: guia prático das propriedades e aplicações. Trad. R. J. Schneider. São Paulo: Melhoramentos. Viver com saúde, 352p.

MIRLEAN, N., ANDRUS, V.E. \& BAISCH, P., 2003, Mercury pollution sources in sediments of Patos Lagoon Estuary, Southern Brazil. Marine Pollution Bulletin, 46: 331-334. http://dx.doi. org/10.1016/s0035-326X(02)00404-6

OLIVEIRA, L.R. Metais pesados e atividade enzimática em Latossolos tratados com lodo de esgoto e cultivados com milho, 2008, Tese (Doutorado em Produção Vegetal) - Faculdade de Ciências Agrárias e Veterinárias, Universidade Estadual Paulista, Jaboticabal, 108p.

PAIVA, M.P., 1997, Recursos pesqueiros estuarinos e marinhos do Brasil. Fortaleza: Ed. UFC. 287 p.

SANTOS, J.A., 2005, Determinação de Cu e Zn em fazendas produtoras de camarão do litoral leste do estado do Ceará. Tese (Mestrado em Ciências Marinhas Tropicais). Universidade Federal do Ceará, Fortaleza, 64p.

WHITE, S.L. \& RAINBOW, P.S., 1984, Zinc flux in Palaemon elegans (Crustacea, Decapoda): molting, individual variation and tissue distribution. Mar. Ecol. Prog. Ser., 19 (1-2): 153-166.

WU, Q., BATLEY, E.G., 1995, Determination of sub-nanomolar concentrations of lead in sea water by adsorptive stripping voltammetry with xylenol orange. Analytica Quim. Acta, (309): 95-101. http://dx.doi.org/10.1016/0003-2670(95)00055-5

WU, X.Y. \& YANG, Y.F., 2011, Heavymetal (Pb, Co, Cd, Cr, Cu, $\mathrm{Fe}, \mathrm{Mn}$ and $\mathrm{Zn}$ ) concentrations in harvest-size white shrimp Litopenaeus vannamei tissues from aquaculture and wild source. J. Food Comp. anal., 24 (1): 62-65. http://dx.doi.org/10.1016/j. jfca.2010.03.030 